\title{
Dondurulmuş - Çözülmüş Embriyo Sikluslarında Anne Yaşına Göre Optimum Transfer Gününün Belirlenmesi
}

\author{
Determination of Optimum Transfer Day According to Mother's Age in Frozen-Thawed Embryo Cycles
}

\author{
Seda KARABULUT ${ }^{1,2}$, Oya KORKMAZ ${ }^{1,2}$, Nuri DELIKARA ${ }^{3}$, İlknur KESKİN ${ }^{1,2}$
}

1. İstanbul Medipol Üniversitesi, Tıp Fakültesi, Temel Tıp Bilimleri Bölümü, Histoloji ve Embriyoloji ABD, İstanbul, Türkiye

2. Istanbul Medipol Üniversitesi, Rejeneratif ve Restoratif Tıp Araștırmaları Merkezi, REMER, Istanbul, Türkiye

3. Florence Nightingale Hastanesi, Tüp Bebek Merkezi, Kadiköy, Istanbul, Türkiye

\section{$\ddot{O Z Z T}$}

Amaç: Bu çalışmamızda, dondurma çözme sikluslarında anne yaşıına göre transfer gününün etkisini inceleyerek hangi yaş grubunda hangi embriyo transfer gününün daha etkili olduğunun araştırılması amaçlanmıştır.

Materyal ve Metod: 205 çift retrospektif olarak incelenerek çalışmaya alınmıştır. Hastalar anne yaşına göre 3 gruba bölünmüştür. Birinci grup 30 yaş altı 63 hastadan, 2. grup 30-37 yaşa arast 109 hastadan ve 3. grup 37 yassindan büyük 33 hastadan oluşmuştur. Her bir gruptaki hastalar embriyo transferlerinin 3. ya da 5. günde yapılmış olmasına bağlı olarak ayrılmış ve gebelik oranları belirlenmiștir.

Bulgular: 1. ve 2. gruplarda gebelik oranlart arasinda istatistiksel olarak anlamlı bir fark belirlenmemesine karşıllı (\%38.7 $\% 31.2$ ve \%31.6, \%30.6 sirasiyla) 3. grupta 3. gün transferindeki başart oranının 5. güne göre yaklaşık 2.5 kat daha fazla olduğu (\%28 - \%12.5 sirasiyla) belirlenmiștir.

Sonuc: 30 yas altı ve 30-37 yas arası hastalarda transfer gününün sonuçları etkilemediği ancak 37 yaşından büyük ileri yaş grubunda 3. gün embriyo transferlerinin daha iyi gebelik sonucu verdiği gözlemlenmiştir.

Anahtar Kelimeler: embriyo transfer günü, embriyo gelişimi, ICSI, maternal yaş

\section{ABSTRACT}

Objective: In this study, it was aimed to investigate the effect of transfer day according to the maternal age in freeze-thaw cycles to determine which embryo transfer day is more effective in different age groups.

Material and Methods: Twenty-five pairs were retrospectively examined. Patients were divided into 3 groups according to maternal age. The first group consisted of 63 patients under 30 years old, the second group was 109 patients between 30-37 years, and the third group consisted of 33 patients aged 37 years and over. Patients in each group were separated according to the embryo transfer ( $3 r d$ or 5th) day and pregnancy rates were determined.

Results: Although there were no statistically significant difference between the pregnancy rates in the first and second groups $(38.7 \%, 31.2 \%$ and $31.6 \%$, respectively, $30.6 \%)$, the success rate in the third group was about 2.5 times higher in the $3 \mathrm{rd}$ day ET than in the fifth day (28\% - $12.5 \%$ respectively).

Conclusion: It was observed that maternal age of $\geq 30$ and 30 -37 years, transfer day did not affect the pregnancy results, however, $3 \mathrm{rd}$ day ET gave better pregnancy outcome in the patients aged 37 years and over.

Keywords: embryo transfer day, embryo development, ICSI, maternal age

\section{İletişim Bilgileri}

Sorumlu Yazar: Oya KORKMAZ, Arş. Gör.

Yazışma Adresi: İstanbul Medipol Üniversitesi, Tıp Fakültesi Temel Tıp Bilimleri Böl, Histoloji ve Embriyoloji ABD, Kavacık Mh. Ekinciler Cad. No:19 34810 Beykoz, iSTANBUL, Türkiye E-posta: oyakorkmaz@medipol.edu.tr

Tel: +90 (506) 14748 11)

Makale Geliş Tarihi: 08.08.2017

Makale Kabul Tarihi: 08.09.2017

DOI: http://dx.doi.org/10.16948/zktipb.332476

\section{GİRIŞ}

Yardımla üreme teknikleri grubuna giren intrasitoplazmik sperm enjeksiyonu (ICSI) infertilite tedavisinde kullanılan yöntemlerden biridir. Yöntem, ovulasyon indüksiyonu ile stimüle edilen ovaryumlardan oosit toplama işlemiyle cerrahi olarak oosit elde edilmesi ve elde edilen oositlerin hazırlanan sperm hücreleriyle inverted mikroskop altında mekanik olarak birleştirilmesi esasına dayanır. Fertilize olan oositlerden elde edilen embriyoların bir k1smı transfer edilmekte, geriye kalan uygun kalitedeki embriyolar ise ÜYTE yönetmeliğine uygun olarak çiftin onayı alınarak dondurulabilmektedir. Dondurulan embriyolar 5 yıla kadar saklanabilmekte, bu süre içinde uygun koșullar sağlandığında çözülerek transfer edilebilmekte ve bu yolla gebelik elde edilebilmektedir (1).

Gebelik oluşmadığında hastaların uzun ve zor bir stimülasyon sürecini yaşamadan embriyolarını kullanabilmeleri, dondurulmuş embriyo transferi sürecinin çok daha kolay bir hazırlık döneminin olması, operasyon risklerini içermemesi, maliyetinin çok daha düşük olması ve artan embriyoların etik tartışmalara neden olabilecek imha islemine maruz kalmaması yöntemin önemli avantajları olarak sıralanabilmektedir (1).

Dondurma çözme sonrası başarı oranları geçmiş yıllarda taze sikluslara göre biraz daha düşük bildirilmiş olmasına rağmen $(2,3,4)$, dondurma yöntemleri ve medyumlardaki gelişmelere bağlı olarak son yıllarda hızla artmış hatta son çalışmalarda taze siklusa göre tüm embriyoların dondurularak daha sonra transfer edilerek daha başarılı sonuçlar alınabileceği iddia edilmiştir $(5,6,7)$. Bu durum, taze siklus sırasında kullanılan hormon ilaçlarının ve foliküllerden salgilanan yüksek düzeyde östrojenin implantasyonu olumsuz etkilediği görüşü ile açıklanmaktadır.

Embriyo dondurma aynı zamanda fertilitenin korunması başlığı altında incelendiğinde önemi daha da artmaktadır. Kanser gibi fertiliteyi olumsuz yönde etkileyecek çeşitli hastalıklar, oosit rezervinin azalması ya da bitmesi, sperm sayısının çok az olması ya da testiküler sperm kullanımı nedeniyle tekrar sperm bulma ihtimali az olan vakalarda elde edilen embriyoların başarılı bir şekilde dondurulup çözülmesi ve transfer sonrası başarı oranlarının kabul edilebilir seviyelere çıkartılması fertilitenin uzun süreler korunabilmesi açısından çok büyük önem arz etmektedir. 
Dondurma çözme sonrası başarı oranları, dondurulan embriyonun kalitesi, dondurma günü, kullanılan medyum, dondurma tekniği, çözme tekniği, çözme medyumu, çözme günü, uygulayan kişi, transfer günü, stimülasyon protokolleri, genetik faktörler ve anne yaşı gibi birçok parametreden etkilenmektedir. Bir tüp bebek merkezinin başarılı bir dondurma-çözme politikası oluşturması için tüm bu süreçlerin optimize edilmesi ve en uygun yöntemin standardize edilmesi gerekmektedir.

Çalışmamızda, dondurma çözme sikluslarında anne yaşına göre transfer gününün etkisini inceleyerek hangi yaş grubunda hangi embriyo transfer gününün daha etkili olduğunun araştırılması hedeflenmiştir.

\section{GEREÇ ve YÖNTEM}

\section{Çalışma Dizaynı}

Merkezimizde farklı endikasyonlardan dolayı ICSI denemesi yapılan, kalan embriyoları dondurulan ve dondurulmuş embriyoları çözülerek transfer edilen 205 çift retrospektif olarak incelenerek çalışmaya alınmıştır. Hastalar anne yaşına göre 3 gruba bölünmüştür. Birinci grup 30 yaş altı 63 hastadan, 2 . grup 30-37 yaşa arası 109 hastadan ve 3. grup 37 yaşından büyük 33 hastadan oluşmuştur. Her bir gruptaki hastalar embriyo transferlerinin 3. ya da 5. günde yapılmış olmasına bağlı olarak ayrılmış ve gebelik oranları belirlenmiştir. Her grup için gebelik oranları arasındaki olası farklar istatistiksel olarak değerlendirilmiştir.

\section{Ovülasyon indüksiyonu ve ICSI}

Bütün hastalara, gonadotrophin-releasing hormon (GnRH) analoglariyla kısa ya da uzun kontrollü ovaryan stimülasyon protokolü uyguland. Foliküllerin gelişmesi için human menopozal gonadotropin (HMG) ya da rekombinant folikül stimülasyon hormonu (FSH) kullanıldı. Oositler 10000 IU hcG enjeksiyonundan 36 saat sonra tranvajinal yolla ultrasonografi eşliğinde topland. Spermler $\% 90$ ve $\% 45$ 'lik density gradientcvbn:çö (PureSperm, Nidacon, Sweden) yöntemiyle hazırlandi. Toplanan oositler enzimatik (Hyase 10X, Vitrolife, Kungsbacka, Sweden) yöntemle soyularak Narishige mikroenjeksiyon sistemi ataçmanlı ve Hoffman modülasyonlu inverted mikroskop (Olympus IX71, Japan) kullanılarak mikroenjekte edildi. Mikroenjeksiyon işlemi Van Steirteghem ve ark. tarafindan belirtildiği şekilde uygulandı
(6). Enjekte edilen oositler sequential kültür medyumunda (Sage media, Origio) inkübe edildi. Embriyo transferleri gelişen embriyoların sayısı ve kalitesine göre 3. ya da 5. günde gerçekleştirildi. Embriyo transfer işleminden 12 gün sonra kandaki $\beta$-hCG seviyesi ölçülerek gebelik oluşup oluşmadığı belirlendi. 10 $\mathrm{mIU} / \mathrm{ml} \beta$-hCG değeri pozitif gebelik olarak değerlendirildi. Veriler Windows 10.0 için SPSS (Statiscal Package for Social Sciences) programı kullanılarak değerlendirildi. $\mathrm{p}<0.05$ değeri istatistiksel olarak anlamlı kabul edildi.

\section{Embriyo Dondurma ve Çözme}

Embriyolar vitrifikasyon yöntemiyle aynı kişi tarafından dondurulmuş ve çözülmüştür. Embriyo vitrifikasyonu; Embriyoların dondurulması için işlemden önce petriye equilibration solüsyon (ES) 100 $\mu \mathrm{l}$ ve vitrification solüsyon (VS) $200 \mu \mathrm{l}$ lik droplar yapılarak oda 1sısında 10-20 dk bekletildi. Süre dolunca embriyolar mikro pipet yardimı ile ES ye aktarıldı ve ES de 10-14 dk (2. Gün, 3. Gün ve 4. Gün embriyolar 10-12 dk ve Blastosist embriyolar $12-14 d k$ ) bekletildi. Süre dolunca embriyolar VS ye aktarıldı, embriyolar VS içinde 3-5 defa yıkandı ve $1 \mathrm{dk}$ içinde cryovial veya straw'a yüklendi. Bütün işlemler oda 1sısında yapıldı. Cryovial'e yüklenen embriyolar sıv1 azota (LN2) daldırıldı ve işlem sonrası embriyolar saklama tankına kaldırıldı.

\section{Embriyo Thawing}

Embriyoların çözdürülmesi için işlemden önce 1. petriye Thawing (TS) solüsyondan 0,5 ml'lik drop yap1ld1 ve $37^{\circ} \mathrm{C}$ 'de etüvde $30 \mathrm{dk}$ beklendi. 2. petriye diluent solüsyondan (DS) $200 \mu \mathrm{l}$ lik 1 drop ve washing solüsyondan (WS) $100 \mu \mathrm{l}$ lik 2 drop yapılarak oda 1sısında beklendi. Süre dolunca sıv1 azot içinden alındı ve sıra ile TS de $1 \mathrm{dk}$ (işlem $37{ }^{\circ} \mathrm{C}$ 'de olacak), DS de $3 \mathrm{dk}$, WS1 de $3 \mathrm{dk}$ ve WS2 de $3 \mathrm{dk}$ bekletildi. Embriyolar WS2 den sonra kültür ortamına aktarılıp vitalite vekaliteleri değerlendirildi.

\section{BULGULAR}

Her gruptaki hasta dağılımları ve gebelik sonuçları Tablo 1 de gösterilmiştir. 1. ve 2. gruplarda gebelik oranları arasında istatistiksel olarak anlamlı bir fark belirlenmemesine karşılık (\%38.7, \%31.2 ve $\% 31.6, \% 30.6$ sirasiyla) 3. grupta 3. gün transferindeki başarı oranının 5. güne göre yaklaşı1 2.5 kat daha fazla olduğu (\%28 - \%12.5 sırasıly) belirlenmiştir.

Tablo 1: 3 Hasta Grubunun Dağılımları ve Gebelik Sonuçları.

\begin{tabular}{|c|c|c|c|c|c|c|c|c|c|c|c|c|}
\hline Hasta Grupları & \multicolumn{4}{|c|}{ Grup } & \multicolumn{4}{|c|}{ Grup } & \multicolumn{4}{|c|}{ Grup } \\
\hline Yaş & \multicolumn{4}{|c|}{$<30$} & \multicolumn{4}{|c|}{ 30-37 } & \multicolumn{4}{|c|}{$>37$} \\
\hline Toplam Hasta Sayısı & \multicolumn{4}{|c|}{63} & \multicolumn{4}{|c|}{109} & \multicolumn{4}{|c|}{33} \\
\hline Embriyo Transfer Günü & \multicolumn{2}{|c|}{ 3. Gün } & \multicolumn{2}{|c|}{ 5. Gün } & \multicolumn{2}{|c|}{ 3. Gün } & \multicolumn{2}{|c|}{ 5. Gün } & \multicolumn{2}{|c|}{ 3. Gün } & \multicolumn{2}{|c|}{ 5. Gün } \\
\hline \multirow[t]{2}{*}{ Hasta Sayısı } & \multicolumn{2}{|c|}{31} & \multicolumn{2}{|c|}{32} & \multicolumn{2}{|c|}{60} & \multicolumn{2}{|c|}{49} & \multicolumn{2}{|c|}{25} & \multicolumn{2}{|c|}{8} \\
\hline & $\begin{array}{c}\operatorname{Pr}(+) \\
12\end{array}$ & $\begin{array}{c}\operatorname{Pr}(-) \\
19\end{array}$ & $\begin{array}{c}\operatorname{Pr}(+) \\
10\end{array}$ & $\begin{array}{c}\operatorname{Pr}(-) \\
22\end{array}$ & $\begin{array}{c}\operatorname{Pr}(+) \\
19\end{array}$ & $\begin{array}{c}\operatorname{Pr}(-) \\
41\end{array}$ & $\begin{array}{c}\operatorname{Pr}(+) \\
15\end{array}$ & $\begin{array}{c}\operatorname{Pr}(-) \\
34\end{array}$ & $\begin{array}{c}\operatorname{Pr}(+) \\
7\end{array}$ & $\begin{array}{c}\operatorname{Pr}(-) \\
18\end{array}$ & $\begin{array}{c}\operatorname{Pr}(+) \\
1\end{array}$ & $\operatorname{Pr}(-)$ \\
\hline Gebelik Oranı (\%) & \multicolumn{2}{|c|}{38.7} & \multicolumn{2}{|c|}{31.2} & & & \multicolumn{2}{|c|}{30.6} & \multicolumn{2}{|c|}{28} & \multicolumn{2}{|c|}{12.5} \\
\hline$p$ değeri & \multicolumn{4}{|c|}{$>0.05$} & \multicolumn{4}{|c|}{$>0.05$} & \multicolumn{4}{|c|}{$<0.05$} \\
\hline
\end{tabular}




\section{TARTIŞMA}

ICSI sonras1 embriyoların implantasyonunun maksimum olduğu transfer gününün belirlenmesi tartışma konusudur. Embriyo kültür sistemleri ve başarı oranlarının artmaya başlamasıyla birlikte embriyoların daha uzun süreli kültür edilmeleri olanaklı hale gelmiştir. Eskiden rutin olarak 2. ya da 3. günlerde yapılan embriyo transferleri, artık 5. ya da 6 . günlerde blastosist aşamasında yapılabilmektedir. Embriyo genomunun 3. günde aktive olduğu ve blastosist aşamasına gelen embriyoların bu nedenle daha fazla implante olabilme ve daha iyi embriyonik gelişim gösterebilme potansiyeline sahip olduğu iddia edilmektedir. $\mathrm{Bu}$ nedenle blastosist aşamasına ulaşma oranları düşük olsa da embriyo transferlerinin bu günlerde yapılması tercih edilmiştir. Bu amaçla bazı gruplar seçilmiş hasta gruplarında (anne yaşının 35 yaşından küçük, oosit sayısı ve kalitesinin yüksek olduğu) blastosist aşamasında transferi tercih ederken bazı gruplar poor responder olarak adlandırılan hasta gruplarında dahil (ileri anne yaşı, az ve kalitesiz embriyoya sahip hastalar) blastosist transferini tercih etmektedirler $(2,3,6)$. Benzer şekilde dondurulmuş embriyo transferlerinde de tartışma devam etmektedir $(4,5,8)$. Taze embriyolara göre yaşama oranları daha düşük olan dondurulup-çözülmüş embriyoların 5. Gün transfer edilmesinin daha faydalı olabileceği ileri sürülmüştür.

Çalışmamızın bulguları doğrultusunda 30 yaş altı ve 30-37 yaş arası hastalarda transfer gününün sonuçları etkilemediği ancak 37 yaşından büyük ileri yaş grubunda 3. gün embriyo transferlerinin daha iyi gebelik sonucu verdiği gözlemlenmiştir. Bu sonuçlar doğrultusunda ileri yaş grubunda embriyoların blastosist aşamasına kadar ulaşabilmelerine rağmen implantasyon potansiyellerinin az olduğunu söyleyebiliriz. Bunun nedeni olarak da rahim içi ortamın bizim taklit edebildiğimizden çok daha optimum olmasından kaynaklanabileceğini iddia edebiliriz.

Sonuç olarak, 37 yaş üstü ileri anne yaşı grubunda embriyo transfer günü olarak 3 . gün tercih edilmeli, blastosist aşamasına gidilebilmesine rağmen in vivo ortamın olumlu etkisi göz ardı edilmemelidir.

\section{KA YNAKLAR}

1. Van Steirteghem AC, Liu J, Joris H, Nagy Z, Janssenswillen C, Tournaye H, Derde MP, Van Assche E, Devroey P. Higher success rate by intracytoplasmic sperm injection than by subzonal insemination. Report of a second series of 300 consecutive treatment cycles. Hum Reprod. 1993 Jul;8(7):1055-60.

2. De Vos A, Van Landuyt L, Santos Ribeiro S, Camus M, Van de Velde H, Tournaye H, Verheyen $G$. Cumulative live birth rates after fresh and vitrified cleavage-stage versus blastocyst-stage embryo transfer in the first treatment cycle. Hum Reprod. 2016 Nov;31(11):2442-2449.

3. Veeck LL, Bodine R, Clarke RN, Berrios R, Libraro J, Moschini RM, Zaninovic N, Rosenwaks $Z$. High pregnancy rates can be achieved after freezing and thawing human blastocysts. Fertil Steril. 2004 Nov;82(5):1418-27.

4. El-Toukhy T, Kopeika JY, Beebeejaun Y, El Tokhy O, Pundir J, Khalaf Y. Impact of the outcome of fresh blastocyst transfer on the subsequent frozen-thawed blastocyst transfer cycle. Reprod Biomed Online. 2017 Jul 13. pii: S1472-6483(17)30313-9.

5. Sun L, Chen ZH, Yin MN, Deng Y.[Pregnancy and obstetric outcomes of fresh embryo transfer versus frozen-thawed embryo transfer in women below 35 years of age].Nan Fang Yi Ke Da Xие Хие Bao. 2017 Jul 20;37(7):929-932.

6. Wang X, Du M, Guan Y, Wang B, Zhang J, Liu Z. Comparative neonatal outcomes in singleton births from blastocyst transfers or cleavage-stage embryo transfers: a systematic review and meta-analysis. Reprod Biol Endocrinol. 2017 May 4;15(1):36.

7. Adeviye Erşahin A, Acet M(2), Erşahin SS, Dokuzeylül Güngör N. Frozen embryo transfer prevents the detrimental effect of high estrogen on endometrium receptivity. J Turk Ger Gynecol Assoc. 2017 Mar 15;18(1):38-42.

8. Carvalho BR, Barbosa MW, Bonesi H, Gomes DB Sobrinho, Cabral ÍO, Barbosa AC, Silva AA, Iglesias JR, Nakagawa HM. Embryo stage of development is not decisive for reproductive outcomes in frozen-thawed embryo transfer cycles. JBRA Assist Reprod. 2017 Feb 1;21(1):23-26. 